\title{
Flores, cores e formas: 0 Brasil estampado de chita
}

\author{
IVANA GUILHERME SIMILI \\ PRISCILA BARBEIRO
}

\section{Resumo}

No trabalho, a relação entre arte e cultura é examinada por intermédio da análise das apropriações da chita, um tecido que caracteriza a cultura brasileira na criação de visualidades de um livro destinado ao segmento infantil: "Uma festa de cores: Memórias de um tecido brasileiro", de Anna Gobel e Ronaldo Fraga (2014). Da produção visual encontrada no livro, procuramos identificar como os elementos visuais comunicam aos seus leitores características de brasilidades, a partir da história e da apropriação do tecido na narrativa contada na obra. 


\title{
Flowers, colors and shapes: Brazil stamped in chita
}

\section{IVANA GUILHERME SIMILI}

PRISCILA BARBEIRO

\begin{abstract}
At work, the relation between art and culture is examined by means of the analysis of chita appropriations, a cloth that characterizes the Brazilian culture, in the creation of visualities in a book for the children segment: "A party of colors: memories of a Brazilian cloth", by Anna Gobel and Ronaldo Fraga (2004, our translation). From the visual production found in the book, we aimed to identify how the visual elements communicate Brazilian characteristics with the readers, from story and appropriation of cloth in the narrative told in the book.
\end{abstract}

Keywords:

Chita, culture, image 


\title{
Flores, colores y formas: Brasil estampado de percal
}

\author{
IVANA GUILHERME SIMILI \\ PRISCILA BARBEIRO
}

\section{Resumen}

En este trabajo se examina la relación entre el arte y la cultura a través del análisis de las apropiaciones del percal, un tejido que caracteriza la cultura brasileña en la creación de visualidades de un libro destinado al segmento infantil: "Uma festa de cores: Memorias de um tecido brasileiro", de Anna Gobel y Ronaldo Fraga (2014). En la producción visual encontrada en el libro, buscamos identificar cómo los elementos visuales comunican a sus lectores características de brasileidades, partiendo de la historia y de la apropiación Percal, cultura, imagen del tejido en la narrativa contada en la obra. 


\section{Introdução}

Neste estudo buscamos tecer as relações entre um objeto histórico cultural: o tecido chita e os processos de memória e de significação da/para a identidade brasileira. Nesse sentido, optamos por analisar a composição pictórica de imagens culturais por meio da narrativa e da incorporação do tecido nas visualidades presentes em uma história destinada ao segmento infantil. Trata-se da obra Uma festa de cores: Memórias de um tecido brasileiro (2014), de Anna Gobel e Ronaldo Fraga.

O livro conta de forma poética a história de uma personagem simples, chamada chita, presente no dia a dia de nós brasileiros. A narrativa é toda em primeira pessoa feita pela protagonista da história: a chita que conta sua origem e fala de seus antepassados originários da Índia na Idade Média, conhecidos como chintz. Ela narra que a variação dessa nomenclatura nasceu aqui no Brasil, com esse tecido com caráter tropical que conhecemos hoje, com novas padronagens, motivos florais vibrantes, contornos em preto, cores vivas e contrastantes. Na composição visual da obra as imagens rompem estereótipos e exploram linguagens artísticas, tais como as cores, formas, padrões e texturas da chita, construindo figuras e cenários de festas populares como o maracatu, as festas juninas, as danças folclóricas etc. Com este projeto estético, o livro propõe-se a apresentar aos seus/suas leitores/as a história de usos e apropriações desse tecido democrático, de personalidade suficiente para sobreviver à globalização (GOBEL; FRAGA, 2014).

A ilustradora da obra, Anna Gobel, nasceu em Valencia, na Espanha, e quando tinha apenas um ano de idade foi para a Alemanha. Aos cinco anos veio para a América do Sul para morar em Buenos Aires, e então não parou mais de viajar. Veio para o Brasil em 1995 e, hoje, mora em Belo Horizonte, Minas 
Gerais. Atualmente é professora, ilustradora e artista plástica. Suas produções artísticas contemporâneas trabalham com a linguagem pictórica do desenho e da gravura. Gobel conta que é apaixonada pela chita desde que chegou ao Brasil: "A chita, com seu colorido, piscou para mim logo que cheguei ao Brasil" (GOBEL; FRAGA, 2014, p. 42). Desde pequena as festas populares exerciam um fascínio especial sobre ela. Impressionada com a riqueza do tecido, convidou o estilista mineiro Ronaldo Fraga para dar palavras aos seus desenhos.

Ronaldo Fraga, estilista mineiro que nasceu em Belo Horizonte, é um narrador da cultura brasileira que a traduz por meio das linguagens artísticas e da costura de roupas. Fraga criou mais de trinta coleções, celebrando uma interpretação particular das obras de grandes ícones da música, literatura, arte e de outras manifestações artísticas e culturais. Aspecto marcante na trajetória de Ronaldo Fraga é a valorização de suas origens por meio da produção de moda. Em suas criações ele procura manter viva a lembrança de sua infância no interior de Minas Gerais, estado pioneiro na chita, e que ainda continua fabricando o tecido. $\mathrm{O}$ destaque conquistado pelo mineiro no mundo fashion fez com que passasse a usar chita também em suas coleções. Na ótica de Ronaldo, "O sucesso do tecido vem do fato de ele representar um Brasil que a gente quis negar. Nossa identidade só vai ser construída se nos aproximarmos de todas as referências iconográficas brasileiras, conclui" (MELLÃO; IMBROSI, 2005, p. 178).

Na narrativa do estilista é patente a maneira como concebe seus fazeres na moda e o papel que os bens do patrimônio cultural, entre os quais, os tecidos, desempenham na construção de sentidos simbólicos para a formação de ideias e imagens sobre/para a identidade brasileira.

Entre os recursos envolvidos nos processos de construção de identidades estão a história, a memória coletiva, os projetos culturais desenvolvidos pelos indivíduos e pelas sociedades em diversos tempos/espaços. Processos que envolvem as apropriações e as ressignificação de vários elementos simbólicos (CASTELLS, 1999).

Face ao exposto, um livro que escreve a história da chita, como elemento simbólico na história da cultura brasileira, permite entender os caminhos por ela percorridos nos processos das formações das identidades, dentre os quais, aqueles desenvolvidos em diferentes tempos/espaços e que constituem o tecido em emblemas das brasilidades. 
Com este olhar, por meio da produção narrativa feita com e pela chita, encontrada no livro, procuramos identificar como os elementos visuais comunicam aos/às seus/suas leitores/as características de brasilidades de modo a determinar de que maneira a história de um tecido fabricou e fabrica uma história da cultura brasileira.

Deste modo, procuramos revelar as articulações da Arte, tendo como suporte a literatura infantil na construção de significados para a memória e a história da cultura brasileira em suas conexões com o patrimônio. Nesse sentido, como pensa Barbosa (2008), quando nos referimos a Arte, é importante desfazermos estereótipos, principalmente no ensino das artes visuais, no qual a grande maioria reproduz conceitos modernistas largamente difundidos nos meios acadêmicos. Esta metodologia de ensino exclui todas as artes chamadas menores/populares, impossibilitando um trabalho intercultural em arte. Assim, é preciso desvincular a arte e suas produções da dimensão transcendental, na qual a tradição moderna a colocou, superando a concepção museológica da arte e a ideia de belas artes.

No Brasil, Barbosa (2008) vem desenvolvendo uma visão intercultural para o ensino da arte. Seus estudos defendem a ideia de reforçar a herança artística e estética dos alunos com base em sua própria cultura. Para isso, é preciso compreender o contexto histórico das imagens, sabermos que elas são fruto de uma cultura e de um modo de vida, podendo apresentar um conjunto de símbolos e artefatos com os quais os indivíduos se identificam, e possuem um sentimento de pertencimento, funcionando como fonte de significados. Concordamos com o conceito de cultura preconizado pela autora e trazemos para a abordagem da obra de Fraga um de seus princípios de análise, que é o de tentar compreender a cultura e o contexto histórico das suas imagens, manifestações materiais e simbólicas de grande importância para refletirmos sobre o efeito que elas exercem sobre nossas identidades (BARBOSA, 2008).

Portanto, ao enfocarmos o estudo na chita, concebemos esta como objeto histórico da cultura brasileira e, como tal, biográfico-memorialístico, que foi e vem sendo apropriado e ressignificado na modernidade, neste caso em específico, apresentado na linguagem artística das ilustrações como narrativas visuais e culturais.

Deste modo, o interesse neste texto e suas contribuições se orientam pela descoberta de possibilidades para a ampliação do conceito de arte, de um sentido mais restrito e excludente, 
para um sentido mais amplo, no qual, nos voltamos à análise de um elemento imagético presente na vida comum, de grande valor estético para nossa cultura, que é a chita. É a história que a chita escreve sobre/para a cultura brasileira, em suas redes de apropriações e de significações, que procuramos deslindar no livro de Fraga.

\section{Estampa chita: a brasilidade em cores e formas}

A história da chita é a narrativa das apropriações do tecido nas práticas de vestir e de produzir roupas. Dessa história emerge a representação caracterizadora do tecido como elemento simbólico da identidade brasileira, de suas narrativas emergem estampas que desenham e definem os teores das brasilidades.

Nessa história, a chita serviu para vestir as escravas e as manequins nas passarelas dos desfiles de moda. Foi estampa da elite e estampa de forrar mesa da cozinha. Conhecida como pano popular passou pela literatura, pelo cinema e pelas manifestações artísticas. Vestiu movimentos culturais, coloriu festas populares, participou de tradições religiosas, tornando-se símbolo da moda brasileira. A lembrança da chita é signo de uma brasilidade associada ao nosso ambiente tropical, logo, pensar em chita é ver a alegria descarada da combinação de suas cores e das misturas descontroladas de estampas, a alegria genuína do povo brasileiro que viveu história de castigo, festa, trabalho e arte (MELLÃO; IMBROSI, 2005).

A história da chita, hoje com esse caráter tropical que o Brasil lhe deu, começa do outro lado do mundo, séculos atrás, há pouco mais de quinhentos anos na Índia medieval. Conhecido como Chint em híndi, língua derivada do sânscrito, que significa pinta ou mancha e caracteriza a estampa predominantemente floral. A estampa chita foi levada à Europa através da expedição de Vasco da Gama, que por ocasião de sua chegada em Calcutá, em 22 de março de 1498, encontrou tecidos de algodão estampados, que encantaram toda a sua tripulação. Pimenta, cravo, canela, açafrão e curry, não foram os únicos sonhos da Europa quinhentista, quando conheceram o algodão estampado, vários povos europeus ficaram fascinados pelo tecido indiano; como os holandeses, ingleses e franceses, os portugueses encantaram-se com a comercialização. Em função da tomada de Constantinopla pelos Turcos, Portugal passou a estabelecer comércio pelo Cabo da Boa Esperança ao sul da África. Logo, esse tecido foi intensamente comercia- 
lizado, dando início a indústrias têxteis e de estamparia em toda a Europa (MELLÃO; IMBROSI, 2005).

A disseminação dos tecidos indianos pelos países europeus proporcionou diferentes interpretações e variações. $\mathrm{Na}$ França no século XVII, surge um descendente da chita indiana, um tecido leve e florido conhecido como Provençal, por ter origem na região de Provence, caracterizando as sedas, brocados e algodões com delicadas estampas de flores. A Inglaterra não só aperfeiçoou seus padrões, como também aprimorou técnicas e máquinas, desenvolvendo novos motivos botânicos de inspiração asiática, com flores e folhagens miúdas, dando origem a outro descendente da chita, o Liberty inglês. Em Portugal, o tecido ficou conhecido como "pintado" e surgiu também uma variante, a "Chita de Alcobaça", que até hoje é produzida. Com estampas florais predominantes, porém, existem figuras humanas, animais e frutos, em diferentes cores, divididas por listras largas formando as molduras características do tecido. As peças são feitas nas dimensões de colchas ou lenços, e até hoje é possível identificar a inspiração indiana original, mesmo com a estilização dos motivos orientais e a utilização de cores diferentes.

Segundo os autores Mellão e Imbrosi (2005), no Brasil a história da chita, embora acompanhe a trajetória das Grandes Navegações, mistura-se também às produções nativas das Américas, visto que seus povos já teciam algodões estampados em tons de vermelho, amarelo, azul, verde e preto. $\mathrm{O}$ próprio algodão, matéria-prima de todas as chitas, já era produzido pelos índios quando Cabral aportou na Bahia, eles o fiavam, teciam e tingiam com pau-brasil, anileira e outras plantas, para ser usado em redes e faixas.

Neste período os europeus que vieram morar no Brasil colônia tiveram que buscar outras opções para as vestimentas trazidas, pois estas eram muito pesadas e quentes para o clima e inadequadas para os trabalhadores. Segundo Chataignier (2010), os caminhos que levavam até as suas casas, o calor de um país tropical, a dificuldade de lavar suas roupas ou mesmo mantê-las limpas, foram os principais motivos para simplificação das vestimentas de moda. A princípio, a maioria das roupas femininas era nas cores preta e marrom, por causa das dificuldades anteriormente mencionadas, mas depois do nascimento das cidades, o algodão estampado, conhecido como chita, ganhou presença no vestuário. Aos poucos os trajes começaram a apresentar adequações necessárias ao novo 
ambiente, introduzindo aos tradicionais trajes lusitanos o despojamento no vestir exigido pelo clima tropical brasileiro.

Os escravos que vieram da África para o Brasil por meio do tráfico negreiro não possuíam vestimentas características de sua cultura, chegavam de navio na costa brasileira usando apenas trapos. Assim, também tiveram que buscar opções nas vestimentas aqui encontradas:

As vestes coloridas e cheias de referências culturais ficaram do outro lado do Atlântico. Observa-se que a indumentária utilizada pelos escravos no Brasil, bem como as que vestiam em sua terra natal, eram feitas de algodão. Não seriam exatamente trajes, mas sim panos em tamanhos variados, formando faixas enroladas entre a cintura e a parte superior das pernas, como se fosse uma saia curta ajustada (CHATAIGNIER, 2010, p. 36).

O algodão brasileiro foi muito utilizado tanto em vestimentas para escravos quanto no fabrico de têxteis para uso doméstico das classes superiores. A partir do momento em que a chita vestiu escravos, fica evidente a denotação que acabou permanecendo ao longo do tempo de "tecido dos desvalidos", "tecido de qualidade inferior" ou "tecido barato", significados estes, atribuídos à estampa chita, que foram responsáveis por situá-la como "pano popular" (SILVA, 2010).

No século XVIII, os mineiros desenvolviam grandemente suas manufaturas e chegavam a produzir tecidos de tão boa qualidade que as populações de outras capitanias começaram a comprá-los. Esse comércio não agradou a metrópole, pois para Portugal não era interessante que uma capitania da colônia se tornasse independente dos produtos de exportação portugueses. Para dar fim ao perigo que a tecelagem mineira representava e, também, para satisfazer os tecelões portugueses que se queixavam da queda na exportação de seus produtos para o Brasil, a rainha Dona Maria I, a louca, em 1785, expediu o alvará proibindo qualquer tipo de manufatura no Brasil e ordenando que todos os teares fossem levados a Portugal. Os poucos teares que existiam na clandestinidade eram utilizados pelos escravos, índios e mestiços, o que talvez possa ser visto como o prenúncio da relação da chita com o povo.

Conforme relatam os autores Mellão e Imbrosi (2005), em 1808, com a chegada do príncipe regente Dom João ao Rio de Janeiro, que autorizou a produção de atividades manufatureiras, a estamparia em tecidos começou a desenvolver-se novamente. Nos anos que se seguiram, com a abolição da escrava- 
tura em 1888, houve uma grande demanda de trabalhadores assalariados, principalmente imigrantes italianos que vinham para o Brasil para trabalharem nas lavouras de café. No entanto, esses imigrantes preferiam vestir-se com as roupas de seu país de origem, fossem ou não adequadas à nova terra. Além disso, esses novos habitantes não queriam identificar-se como uma classe pobre, ex-escravos ou populações rurais, que usavam o algodão, dessa forma, a chita nesse período permaneceu restrita ao "povo brasileiro".

Nas primeiras décadas do século XX, o Brasil viveu uma fase intensa de desenvolvimento graças às inovações técnicas que facilitavam o crescimento de novas indústrias, entre elas as têxteis. Nesse período, a Primeira Guerra Mundial trouxe efeitos benéficos para a produção industrial brasileira. As importações de produtos manufaturados foram suspensas, assim, o Brasil foi obrigado a explorar ao máximo a sua capacidade produtiva, abastecendo o mercado interno e aumentando o volume das exportações. O país começou a ocupar lugar de destaque no comércio internacional de produtos manufaturados. No final do conflito, a indústria têxtil nacional fornecia $85 \%$ dos tecidos de algodão consumidos internamente.

Em 1955, Juscelino Kubitschek assumiu a presidência e estabeleceu o Plano de Metas, incentivando a diversificação da produção nacional e dando início à construção de Brasília. Foi a época de maior otimismo que o Brasil já havia assistido, com um surto de desenvolvimento industrial e modernização. No final da década de 1950, a Fiação e Tecelagem São Jorge voltou-se à demanda específica de sua clientela, principalmente dos que trabalhavam com tecidos para decoração, e começou a fazer testes para fabricar tecidos, entre os quais, a chita com largura maior:

Até então, as peças tinham sessenta, no máximo noventa centímetros, limite determinado pela dimensão dos teares utilizados no Brasil. Foram então cortados dois teares de noventa centímetros remontados, para permitir tecer peças com 1,2 metros de largura (MELLÃO; IMBROSI, 2005, p. 115).

A essa nova chita, deu-se o nome de chitão, que foi muito divulgado na década de 1960, voltado principalmente à fabricação de colchões. "Hoje, o que caracteriza o chitão são as dimensões e as cores de suas estampas florais. Se alguém fizer essa estampa sobre outro suporte que não seja o morim, certamente a referência do novo tecido será 'estampa chitão"' 
(MELLÃO; IMBROSI, 2005, p. 118). Segundo o relato de José Henrique Mascarenhas, diretor da Fabril Mascarenhas, o aumento de tamanho dos motivos estampados teve muito mais a ver com a tecnologia disponível do que com opções estéticas. É impossível precisar exatamente quando o chitão ganhou as cores vivas que tem hoje e até mesmo a dimensão dos motivos florais, tudo o que há são especulações. Uma delas diz respeito ao fato de que nas décadas de 1950/1960, as estamparias conseguiam utilizar no máximo seis cores de cada vez, assim, talvez o uso de cores vivas fosse uma alternativa frente à impossibilidade de misturar mais de seis tonalidades, obtendo-se, dessa forma, uma estampa vibrante. Uma das dificuldades para achar o autor ou a empresa que primeiro tingiu o chitão com as atuais características está na ausência total de patentes de estampas.

No que diz respeito à fabricação da estampa, era comum ampliar uma flor de chita para utilizá-la no chitão, conforme revela a estampadora mineira Jaqueline Mendes, que utilizou um truque manual até pouco mais de dez anos atrás: "Copiávamos a estampa com papel vegetal quadriculado para ampliá-la”, diz, referindo-se ao tempo em que trabalhou na tecelagem Santa Elisabeth, em Belo Horizonte (MELLÃO; IMBROSI, 2005, p. 128). Nessa reciclagem sem fim, de cópias e cópias, perdiam-se os contornos originais, as proporções ou o realismo dos motivos, gerando até flores inusitadas, inexistentes, que convivem placidamente com hibiscos, margaridas, rosas e outras que se reconhecem no chitão. "É possível identificar no tecido, ainda hoje, esse reaproveitamento artesanal, que faz parte do seu charme" (MELLÃO; IMBROSI, 2005, p. 134). Além das estampas florais, começaram a surgir também outras que escapavam dos motivos originais, muitas vezes copiadas de motivos europeus, como flocos de neve, maçãs, ursinhos ou figuras geométricas, podendo ser encontradas facilmente nos dias de hoje.

Surge, nesse período também, o apelido de chita "mamãe - Dolores", para as chitinhas de estampa floral miúda, inspiradas na personagem de mesmo nome da novela de mais sucesso da época, Direito de Nascer, da TV Tupi. Assim, nessa época, o vestidinho de chita tornou-se indispensável para a mulher brasileira: básico, fresquinho e ideal para o verão do nosso país. Logo, a chita, chitinha e chitão começam a ser amplamente produzidos pela maioria das fábricas de tecidos brasileiras, sempre comercializadas por preços baixos, já que o tecido é básico e a fabricação muito simples.

Ainda na década de 1960, período marcado pela revolução nos costumes, no comportamento, na moda, na sexualidade 
e na política; o poder jovem, Flower Power, feminismo, paz e amor e psicodelia, marcavam o cenário dessa época, enquanto nosso país atravessava os chamados anos de chumbo. "As roupas de chitão eram a cara do movimento hippie e o oposto do ufanismo e da repressão militar" (MELLÃO; IMBROSI, 2005, p. 124). A popularidade do tecido, principalmente do chitão, participava do movimento hippie com seu visual florido e colorido, do tropicalismo vestindo Gil, Caetano e Tom Zé, e até no figurino de Chacrinha, um ícone da TV brasileira. Foi também utilizada pela alta costura, tendo como pioneira a adotar a chita a estilista Zuzu Angel, vítima da ditadura, e que usava o tecido em suas coleções ousadas para a época. "A chita no corpo e no cenário dos movimentos artísticos e revolucionários, em plena vitória de repressão, era uma assinatura da alma brasileira, um desafio, quase um descaramento" (MELLÃO; IMBROSI, 2005, p. 127).

A partir do momento em que a chita foi incorporada nas passarelas, livrou-se de estigmas que carregava desde o início de sua fabricação no Brasil: pano de pobre, roupa de caipira, de brincar, tecido ordinário e outros rótulos ficam em segundo plano quando estilistas resolvem vestir top models com as estampas de chita e do chitão.

Como mencionado, a pioneira desse uso diferenciado da chita, a estilista Zuzu Angel, democratizou o universo da alta costura e colocou-a nas ruas. "Em 1959, ela fez saias de chita e zuarte, que é um tecido semelhante, utilizado para forração de colchões; eram baratos, ela estava sem dinheiro. Foi um sucesso" (MELLÃO; IMBROSI, 2005, p. 171). Foi a primeira estilista a falar em identidade brasileira e também a primeira a usar a moda como bandeira política. Muito conhecida no Brasil e nos Estados Unidos por suas coleções que transpiravam brasilidade, Zuzu Angel também era conhecida por sua luta constante contra a ditadura militar brasileira, sua denúncia ao regime militar acabou tirando-lhe a vida.

No final da década de 1970, quando o Rio de Janeiro era a capital da moda de rua brasileira, a chita marcou presença nas criações de um casal de estilistas, Sônia Gallotti e Antônio Bernardo, com seus biquínis e tangas de chitão. Em 1979, a estilista (hoje decoradora) realizou um desfile nos Arcos da Lapa, no Rio, ao final do qual os modelos despiam suas peças de chitão e ficavam nus, segundo ela com a intenção de protestar contra o desaparecimento de presos políticos. "Mais uma vez, fazia-se da chita bandeira liberal" (MELLÃO; IMBROSI, 2005, p. 178). 
A década de 1980 chegou ao fim com a chita fora da indústria da moda e das passarelas. Apenas alguns estilistas viriam a ressuscitá-la, como foi o caso do mineiro Ronaldo Fraga, autor do livro de análise. Em 2001, o estilista apresentou uma coleção em homenagem à grande estilista Zuzu Angel, denominada: “Quem matou Zuzu Angel ?". Esta coleção retrata a luta da estilista contra a ditadura militar brasileira. Foi muito caracterizada pelo uso de chitas de variadas cores e tamanhos, peças com estampas de pássaros e anjos misturavam-se em perfeita harmonia.

Além da indústria da Moda, a chita também foi utilizada por artistas. Em 1992, o Grupo Corpo de Belo Horizonte estreou o espetáculo 21, como pano de fundo do palco uma tela imensa reproduziu em escala teatral detalhes de telas do responsável pela cenografia do espetáculo, o artista plástico Fernando Velloso, cujo tema de sua obra é o Chitão.

Cor e textura são elementos de destaque no trabalho desse artista plástico, professor e cenógrafo mineiro, que combinou técnicas de pintura e colagem numa série de telas com estampas do chitão e outros elementos populares, como o patchwork e o fuxico (artesanato feito com retalhos de tecidos coloridos dobrados) (MELLÃO; IMBROSI, 2005, p. 186).

O espetáculo 21 colocou em cena vertentes criativas que utilizavam a chita como inspiração e referência: cenografia/ figurino e artes plásticas. Outros artistas também transpuseram a tela de morim estampada para a tela de pintura, como Beatriz Milhazes, com suas fortes referências cromáticas que remetem ao Barroco e às estampas de chitão. Na cenografia, outro exemplo é o do diretor, artista gráfico e cenógrafo Gringo Cardia, no show que Elba Ramalho fez no Canecão, Rio de Janeiro, em 1999. "O show era a cultura nordestina de uma maneira pop e esse tecido faz parte do imaginário brasileiro, explica Gringo Cardia” (MELLẪ; IMBROSI, 2005, p. 191). "Eu customizei a chita, bordando com lantejoulas e usando outros recursos. Acho que o trabalho do cenógrafo é colocar no palco uma coisa que as pessoas veem todo dia, mas de forma diferente" (MELLÃO; IMBROSI, 2005, p. 191).

O tecido aparece, de forma previsível, em filmes que retratam a vida no Nordeste. Em outros, porém, pode surgir de forma inusitada, como na capa e no colete de Dom João VI 
(vivido por Marco Nanini) em Carlota Joaquina, dirigido por Carla Camurati. Menos inesperado - mas extremamente marcante - é o uso de uma colcha de chitão vermelho sobre a cama onde Rodrigo Santoro travestido descansa, numa cena de Carandiru, de Hector Babenco. Além do tubinho de chita da novela Gabriela, o tecido tem suas fases sob os refletores das novelas de cada dia. Em Celebridade, a figurinista Marília Carneiro escolheu um conjunto de saia e top de chita da grife carioca Afghan para compor uma baianinha estilizada e vestir a atriz Deborah Secco. A novela Da cor do pecado, ambiente entre Rio e São Luís (Maranhão), abusa do chitão em cenário e figurino (MELLÃO; IMBROSI, 2005, p. 191).

Mesmo enquanto participava de movimentos artísticos e revolucionários, a chita nunca deixou de colorir e enfeitar os festejos que se espalham por todas as regiões deste país imenso. "Nossas festas descendem do sincretismo e miscigenação que faz a cara de nosso país: influências europeias - predominantemente portuguesas -, indígenas e negras se misturam sem o menor pudor ou cerimônia." (MELLÃO; IMBROSI, 2005, p. 145). O tecido se faz presente em celebrações religiosas como as festas juninas com seus vestidinhos rodados e coloridos de quadrilha feitos de chita e chitinha; em atos com origens folclóricas como o bumba-meu-boi maranhense e a Folia de Reis; nas festividades carnavalescas e celebrações com forte conteúdo social, político e também religioso, como o maracatu, que representa a permanência e resistência da cultura africana. Tais festividades representam a miscigenação de várias culturas, a chita é o ícone que melhor traduz o significado de brasilidade presente nestas celebrações folclóricas. Aparecendo em todos os cantos, não importa o lugar em que esteja ela simboliza a alegria, a simplicidade e a sensualidade brasileira. Metaforiza o ambiente aconchegante que só o brasileiro pode produzir. O floral atrai, o colorido vibra.

\section{Chita, cultura e identidade}

Entender o homem brasileiro que busca identidade em meio a tantas culturas distintas em seu território pode ser possível quando se olha para os símbolos que representam a sua brasilidade, e como vimos, a chita fabrica um deles.

A chita destacou-se tanto no cenário brasileiro, que muitas pessoas desconheciam sua verdadeira origem, e acreditavam 
ser um produto originário do Brasil. É importante, então, refletirmos sobre como um objeto estrangeiro se desdobra ao ponto de ser considerado um ícone de nossa identidade nacional.

Nesse desdobramento, os processos de traduções culturais, como definido por Burke (2003), são os trabalhos desenvolvidos por indivíduos ou grupos para domesticar o que é "estrangeiro" por meio de estratégias e de práticas sociais e culturais que envolvem apropriações, adaptações e ressignificações. Processos de tradução que desempenham múltiplas funções nas formações das identidades culturais de grupos e na imagem de nação. Logo, falar em identidade cultural-nacional significa reconhecer que se trata de uma problemática que lida com a percepção de um grupo acerca de si mesmo, de sua história, de seu destino e de suas possibilidades, refletido na sua forma de vida. A identidade cultural está associada a quem somos e a quem queremos ser, nos possibilitando decidir quais de nossas tradições nós queremos continuar e quais não queremos: há uma capacidade de filtragem das tradições; "nossa identidade não é somente algo que nós recebemos; ela é ao mesmo tempo nosso próprio projeto" (MAIA, 2009, p. 104).

Em vários contextos históricos desde o final do século XIX, percebemos que a afirmação de nossa identidade tinha a cultura popular como elemento simbólico fundamental. No entanto, esse tipo de concepção caracteriza-se principalmente na idealização romântica em associar à cultura popular a ideia de tradições. "A cultura popular é heterogênea, as diferentes manifestações folclóricas - reisados, congadas, folias de reis - não partilham um mesmo traço em comum, tampouco se inserem no interior de um sistema único" (ORTIZ, 1985, p. 134). Nesse novo momento, a Cultura, com maiúscula, é substituída por culturas no plural. $\mathrm{O}$ foco não é mais a conciliação de todos, nem a luta por uma cultura em comum, mas as disputas entre as diferentes identidades nacionais, étnicas, sexuais ou regionais. A noção de cultura brasileira vem procurando atualmente enfatizar as diversas matrizes históricas de formação de nossa nacionalidade. Portanto, é corrente a utilização do conceito no plural, ou seja, culturas populares, uma vez que nossa formação é diversa.

Segundo Renato Ortiz (1985), a identidade cultural brasileira está intimamente ligada ao conceito de mestiçagem, ou seja, de misturas raciais e culturais. Essa mescla formaria nossos próprios traços identitários, que se caracterizam no próprio elemento de diversidade. Logo, poderíamos definir a cultura brasileira como o produto da culturação de diversas 
origens. "Ela decorre do sincretismo de diferentes manifestações que hoje podemos identificar como caracteristicamente brasileiras, traduzindo-se num sentido que, embora nacional, tem peculiaridades regionais" (ORTIZ, 1985, p. 93).

Assim, as culturas podem apresentar um conjunto de símbolos, signos e imagens com os quais os indivíduos identificam-se, e possuem um sentimento de pertencimento, funcionando como fonte de significados. Como acredita Hall (2006, p. 76), "as identidades nacionais representam vínculos a lugares, eventos, símbolos, histórias particulares”. Esta relação de pertencimento, muitas vezes, materializa-se nos artefatos produzidos na sociedade.

Sabemos hoje que a ideia de nação como identidade cultural unificada é um mito. As nações modernas são híbridos culturais, juntamente com seus artefatos, símbolos, signos e imagens. O discurso da unidade ou identidade oculta as diferenças de classes, étnicas, religiosas, regionais e etc. Portanto, não existe uma identidade autêntica, mas uma pluralidade de identidades, construídas por diferentes grupos sociais em diferentes momentos históricos. Para além dos termos "mestiçagem", que se refere às misturas raciais, ou "sincretismo", mais relacionado com fusões religiosas, o autor Néstor Garcia Canclini (2011) refere-se à pluralidade de aspectos culturais como Hibridação cultural, que abarca distintas misturas interculturais propriamente modernas. Assim, usa-se esse termo para descrever processos interétnicos e de descolonização, processos que implicam o cruzamento de fronteiras, envolvendo fusões artísticas, literárias e comunicacionais.

Neste âmbito, compreendemos que toda identidade é uma construção simbólica que necessita de elementos construídos historicamente e tomados como representativos; o tecido chita faz-se presente em diversos processos de hibridação cultural, numa interconexão que vai da tradição à modernidade. A história da chita, com sua origem do outro lado do mundo, séculos atrás, desdobrou-se em diferentes processos culturais, sendo por meio de toda sua carga simbólica de usos, desusos e apropriações no Brasil, o ícone que melhor traduz o significado de hibridação brasileira.

Outro ponto importante a ser destacado, é a estética do tecido chita. Quando referimo-nos à estética, diz respeito às características visuais das partes constitutivas do objeto, como a cor, a linha, o tom, a textura, a dimensão, a proporção, a forma e suas relações compositivas. Sobre a estética característica do tecido, o autor Luz Garcia Neira (2012, p. 13) 
comenta que: "[...] os tecidos floridos e coloridos de algodão também são signos de uma brasilidade associada ao ambiente tropical e a alegria do nosso povo, considerada, muitas vezes, o caráter que nos identifica". Faz-se necessário então, refletirmos sobre nossa identidade ser fundamentada nos signos da "natureza". Conforme Ortiz (1985), no Brasil, natureza e nação estão indissoluvelmente ligadas. A identidade nacional está mais ancorada na natureza do que na história. Há um sentimento generalizado que se orgulha mais da natureza, das belezas naturais do meio ambiente, do que da história. Isso é uma atitude cultural que se tornou visível no Romantismo literário que predominou no século XIX e deixou marcas que se estendem até hoje. Portanto, podemos compreender que a associação de identidade cultural brasileira ao tecido chita se dá tanto pela sua historicidade e hibridação quanto pela reprodução da tropicalidade e da natureza estampada visualmente. Hibridação e reprodução que não deixaram registros visuais sobre as apropriações e mutações das estampas, cores, texturas, limitando, assim, os conhecimentos da história da estética do tecido. Todavia, hibridação e reprodução que compõem a história da chita por meio de várias apropriações e construções de sentidos para o consumo real e simbólico do tecido como emblemático da brasilidade ou das tentativas de criar uma identidade para a moda brasileira.

Nesse sentido, importa destacar que com a criação de um mercado brasileiro de moda nos anos 1960, o tema da identidade da roupa brasileira se transformou em ideológico, no sentido de procurar vender uma imagem de Brasil; de que as vestimentas criadas por costureiros brasileiros se diferenciavam daquelas produzidas por europeus e norte-americanos. Nas construções estéticas e discursivas, a brasilidade foi estampada com os símbolos da beleza e da elegância do país e das mulheres (BONADIO, 2014; NEIRA, 2008; SIMILI, 2014).

\section{Uma festa de cores: memórias de um tecido brasileiro}

Definido o objetivo neste texto que é o de compreender as relações entre Arte e Cultura por intermédio das narrativas visuais do livro de literatura infantil, faz-se necessária uma análise das características deste e suas particularidades.

O livro Uma festa de cores: Memórias de um tecido brasileiro (2014) tem por objetivo narrar a história da chita, por meio de falas em primeira pessoa e ilustrações que apresen- 
tam às crianças a trajetória deste tecido tão presente no cotidiano de nós brasileiros. Deste modo, para compreendermos as representações imagéticas da obra, que se utilizam da linguagem artística das ilustrações, é necessário tomarmos como ponto de partida a imagem ilustrativa como via de acesso ao conhecimento. Sabemos que as narrativas visuais são tão antigas quanto o próprio homem, por meio delas o homem contava e registrava os seus feitos cotidianos, desdobrando-se na criação de símbolos gráficos abstratos que deram origem aos fonemas, letras e, por fim, a própria escrita. Essa invenção, embora espetacular, não excluiu nosso interesse pela imagem, ao contrário, escrita e imagem são companheiras no ato de narrar histórias: "Utilizar a imagem como instrumento de linguagem foi - e ainda é - crucial para todos os grupos culturais" (CASTANHA, 2008, p. 141).

É importante lembrar que estudamos ilustrações e não imagens isoladas. Portanto, temos que considerar a relação texto e imagem nos livros infantis, a qual pode variar conforme o propósito do livro. Segundo a autora Ciça Fittipald (2008), há casos em que as ilustrações são projetadas a fim de promover "descansos" do texto, para romper com a monotonia da leitura. Além disso, há casos em que as imagens permeiam alguns pontos do texto, destacando momentos cruciais das histórias. Em outros casos, as imagens e textos dividem igualmente o mesmo espaço do livro; e, por fim, temos os casos em que a imagem é a condutora da narrativa, com textos pequenos ou sem nenhum, onde a visualidade é trabalhada também a partir de uma ferramenta semelhante a um roteiro, que organiza as sequências de ideias imagéticas, tornando possível a leitura e compreensão do livro; esse tipo é o mais utilizado na literatura infantil, visto que as crianças estão iniciando a sua alfabetização. Assim, a obra de análise insere-se neste tipo de literatura, onde a forma pictórica ilustrativa se apresenta como uma tradução das palavras, em linhas, formas, cores e texturas, ressignificando a linguagem verbal para a visual. Dessa forma, os significados do texto se projetam sobre as imagens, assim como os significados das imagens projetam-se sobre o texto.

A partir da ideia da presença da imagem como elemento profundamente significativo, nunca e em nada passivo ou simplesmente decorativo quando inserido numa página de livro, nos propomos a analisar nas imagens os processos de significação da chita na construção de imagens culturais para a narrativa contada na obra. Para tanto, utilizaremos como referência 
de leitura de imagens, os estudos do autor Feldman (1993), que aponta quatro estágios a serem seguidos para a leitura da imagem que, embora distintos, são interligados entre si e não ocorrem necessariamente nessa ordem. São eles: descrição, análise, interpretação e julgamento.

A primeira etapa, a descrição, refere-se a prestar atenção ao que se vê e, a partir da observação, listar apenas o que está evidente. Nesta etapa identifica-se, também, o título da obra, o artista que a fez, o lugar, a época, o material utilizado, a técnica, o estilo ou o sistema de representação, se figurativo ou abstrato etc. Na segunda etapa, a análise, diz respeito ao comportamento dos elementos entre si, como se influenciam e se relacionam. Por exemplo: os espaços, os volumes, as cores, as texturas e a disposição na obra criam contrastes, semelhanças e combinações diferentes que neste momento serão analisadas. O terceiro estágio, da interpretação, é quando procuramos dar sentido ao que se observou, tentando identificar sensações e sentimentos experimentados, buscando estabelecer relações entre a imagem e a realidade, no sentido de apropriar-se da primeira. No quarto estágio, o julgamento, emitimos um juízo de valor a respeito da qualidade de uma imagem e sua importância.

Portanto, selecionamos algumas imagens do livro para análise, a fim de responder: Como os elementos visuais comunicam aos seus leitores características de brasilidades, a partir da história de um tecido que fabricou uma história da cultura brasileira?

Nesta imagem, identificamos cinco círculos com a repetição de um desenho de flor em seu interior, esquematizando um diagrama que indica, por meio de setas, o processo de estamparia da chita, desde seu desenho em preto e branco no primeiro círculo até os outros que aos poucos vão sendo

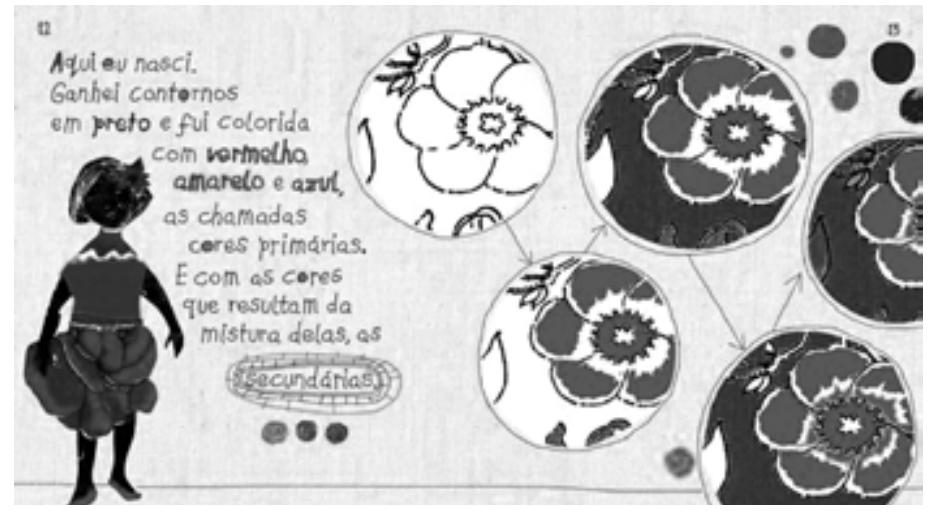


preenchidos por cores. No canto esquerdo, junto ao texto, há também a figura de uma menina feita de recortes de chita, com saia e adereço no cabelo de flor vermelha e algumas bolas coloridas que circulam a imagem. Podemos observar, analisando-as, que as ilustrações seguem a linguagem da colagem, como dito anteriormente, com uma figuração estilizada e círculos irregulares, nos dando a impressão de serem feitos manualmente. $\mathrm{O}$ aspecto artesanal e a realização manual são reforçados nas ilustrações, aproximando-se dessa linguagem tão característica da cultura brasileira, presente nas rendas, bordados, objetos, tapetes de palha trançada, crochês e etc.

$\mathrm{Na}$ interpretação da imagem, o que mais chama atenção é a forma e a coloração do processo de estamparia do tecido. A chita é composta em sua maioria por quatro cores fundamentais: vermelho, azul, amarelo e verde, que preenchem a configuração da flor com contornos em preto. As cores possuem força e são ao mesmo tempo instáveis. Elas são capazes de demonstrar que a mesma parte em tonalidades diferentes não é a mesma, e as sensações são distintas. A forma flor preenchida pela cor vermelha se distingue da mesma forma flor colorida de verde, por exemplo. Na chita vemos confirmadas as ideias da psicologia das cores quanto à relação entre cor e sensação, a alegria das cores, sua luz etc. Assim, suas cores nos trazem sentimentos de nostalgia, de tradição, tropicalidade e de identificação cultural.

A forma "Flor" em questão remete-nos à representação floral irregular bidimensional, grandes ou miúdas, transcritas para o tecido, com a finalidade prática de tampar imperfeições deste. No entanto, as experiências que se formaram nas memórias da chita fizeram com que as flores grandes ou pequenas ultrapassassem este sentido prático, ganhando vida, ou seja, a observação estética da estampa a coloca no segmento prático e utilitário, mas a sua simbologia ultrapassa a funcionalidade. Segundo Arnheim (2006, p. 90):

[...] a forma sempre ultrapassa a função prática das coisas encontrando em sua configuração as qualidades visuais como rotundidade ou agudeza, força ou fragilidade, harmonia ou discordância. Portanto são lidas simbolicamente como imagens da condição humana.

A forma como expressão visual traz para cada observador um significado distinto. Ao trazer para si a imagem, cada expectador coloca na mesma suas impressões e experiências 
subjetivas, na tentativa de decodificá-la. Quando o coletivo começa a identificar a mesma forma ligada ao mesmo significado, a configuração desta forma torna-se simbolismo. Assim, a forma Flor da chita estampada no tecido, ultrapassa o signo e se torna símbolo da brasilidade, uma vez que seu significando é reconhecível a todos.

Ainda nesta ilustração, observamos a composição didática dos elementos e a relação do texto com a imagem. A grafia das cores primárias é contornada pelas cores correspondentes, ressaltando a visualidade dos tons. Há também o resultado das suas misturas, que são as cores secundárias, representadas por paletas de cores logo abaixo da escrita. Portanto, a imagem trabalha, além da visualidade, a correspondência entre texto e imagem, de grande importância para a aprendizagem e a compreensão da mensagem comunicada pela obra.

Figura 2

Fonte: GOBEL; FRAGA

(2014, p. 20)

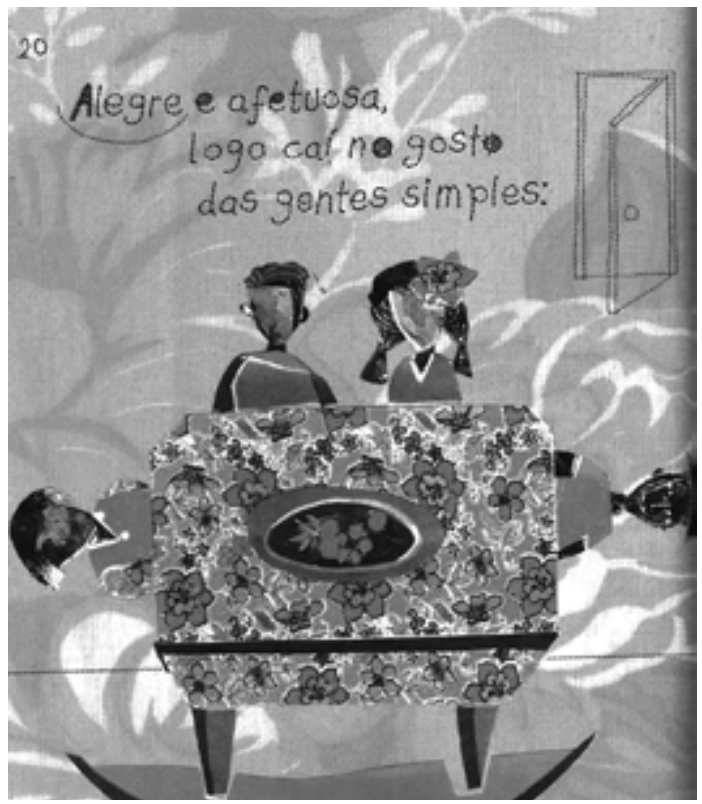

Nesta figura, estão representados quatro personagens sentados em volta de uma mesa coberta por uma toalha de chita amarela de flores vermelhas, azuis e folhas verdes, com uma bandeja de frutas ao centro. As figuras são vistas de cima, numa perspectiva distorcida; e no canto direito podemos identificar um bordado representando uma porta entreaberta sobre um fundo salmão com textura e estampa de tecido floral. Na análise da composição pictórica, a ilustração faz uso 
da colagem, que por meio da sua distorção trabalha a tridimensionalidade. Esta característica compositiva é marcante no Cubismo, que rompe com a perspectiva renascentista, buscando não reproduzir o objeto de um único ponto de vista, mas sim de diferentes ao mesmo tempo, buscando a simultaneidade, em que o tridimensional é reduzido ao plano. Além da referência ao cubismo, a estética do desenho, com os personagens e a mesa voltados para cima, assemelhase aos próprios desenhos infantis, em que as dimensões dos objetos representados não são as do mundo real, são dimensões que obedecem as regras particulares da própria criança e de como ela vê o mundo a sua volta.

No que diz respeito à interpretação da imagem, ela nos traz a sensação do conforto de um lar, onde todos estão a mesa compartilhando um momento familiar. Esta familiaridade e o reconhecimento da chita a nós brasileiros é algo recorrente, ela está presente em diversos segmentos, e principalmente no nosso cotidiano, no dia a dia, na toalha de mesa de nossas casas. Aparentemente, pelo tecido estar intimamente associado ao "gosto das gentes simples", fica evidente a denotação que acabou reverberando ao longo do tempo de "tecido de qualidade inferior" ou "tecido barato", significados estes, atribuídos à estampa chita, que foram os responsáveis por situá-la como popular. No entanto, devido a sua grande popularidade, a chita ultrapassou as conotações pejorativas ao longo do tempo, aparecendo na toalha de mesa, no forro de colchão e na cortina das casas, sendo redimensionada para o consumo da classe média alta, por meio da indústria da moda e do design, que se apropriaram do "gosto popular" para o consumo e por meio desta apropriação ela começa a fazer parte de todos as esferas culturais e sociais.

No que diz respeito aos "gostos", o autor Bourdieu (2007) diz ser este um produto das experiências de vida de grupos e indivíduos envolvidos com as práticas culturais, que são em grande parte determinadas pela trajetória educativa e socializadora dos agentes. Assim, a formação do gosto é um processo social e não fruto de uma sensibilidade inata. Portanto, podemos concluir que o gosto pela chita resultou de uma construção social e histórica, numa relação de internalização e reprodução de preferências estéticas e simbólicas.

É importante salientarmos ainda que as ilustrações rompem com os estereótipos tão disseminados ao público infantil. O estereótipo pode ser considerado uma forma de representação relacionado a processos de condensação, generalização, simplificação 
e homogenização (GOMES, 2002). Ou seja, as crianças e adolescentes têm sua visualidade fortemente influenciada pelas imagens da mídia, cópias e reproduções, que afetam sua imaginação, assim, seus desenhos se arraigam a modelos padronizados, limitando a expressão e a criação de imagens singulares e formas inimaginadas. Portanto, tomando como exemplo a Figura 2 e as ilustrações presentes na obra, podemos caracterizá-las como expressivas, criativas e artísticas, apresentando aos seus leitores e leitoras novas possibilidades de criação de desenhos, com diferentes linguagens compositivas.

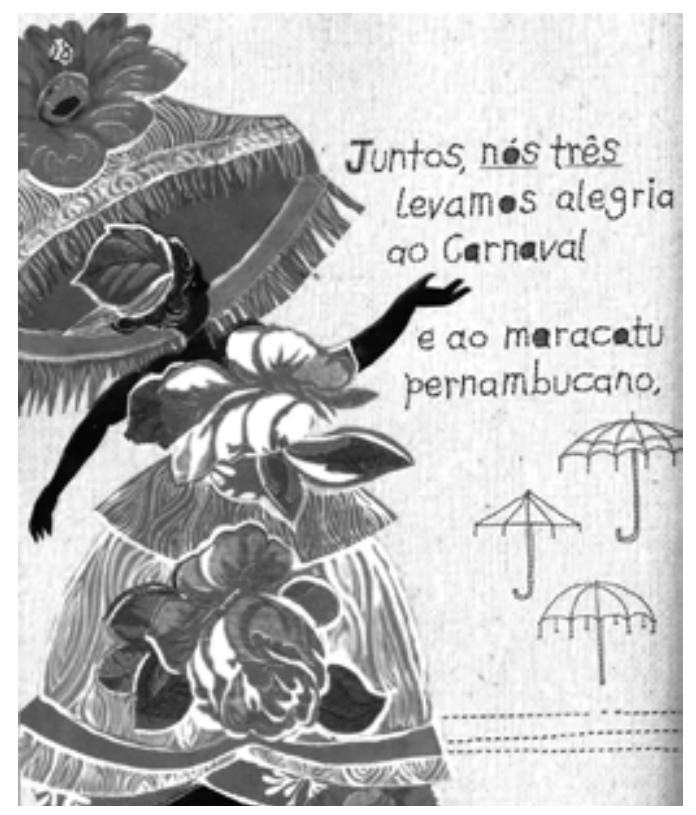

Na Figura 3, identificamos a imagem de uma mulher de perfil, aparentemente em movimentos de dança, com turbante de flor, vestida com trajes coloridos de verde, amarelo e magenta, floridos, tradicionais das festas populares nordestinas. Além da indumentária há também o adereço de guarda-chuva colorido, com flor de chita no centro e franjas circundando-o. Ao lado da figura feminina, a imagem acompanha o texto e abaixo estão representados três modelos de guarda-chuva, fixados no plano de fundo, como se fossem bordados. Abaixo estão linhas formadas por pequenos traços, como se fossem costuradas, sob o fundo com textura de tecido, onde é possível visualizarmos suas tramas. É importante ressaltarmos novamente os detalhes da escrita e dos bordados, que 
contribuem para a relação estabelecida entre a temática da obra e as próprias imagens, ou seja, o bordado, o fazer manual está intimamente associado à ideia de artesanato, ou seja, são técnicas aprendidas de geração a geração e configuram em muitos lugares elemento de identidade cultural comunitária ou regional. A imagem novamente é estilizada, figurativa, utilizando-se da colagem e dos recortes na construção dos personagens ilustrativos. Nesta em específico, é visível a influência da cultura africana, uma vez que a imagem representa uma mulher negra, com seu traje típico, usado em celebrações religiosas e culturais, como é o caso do Carnaval e do Maracatu pernambucano.

Na interpretação da imagem, é visível que há a apropriação do estilo indumentário das mulheres baianas, com seus trajes típicos usados desde o período colonial até atualmente.

Produção e reprodução de sentidos para a brasilidade das mulheres negras e baianas amalgam a imagem. Nessas construções, as indumentárias aproximam e diferenciam os segmentos femininos regionais e nacionais, tais como as baianas de Salvador; aquelas do Carnaval e do Maracatu.

Um importante ponto a ser destacado é a apropriação das vestimentas baianas por Carmem Miranda, uma cantora que representou o Brasil no exterior, tornando-se símbolo de nossa identidade nacional. Em seu figurino, Carmem Miranda esbanjava sensualidade, selecionando peças do vestuário das baianas e acrescentando outros: fios de contas no pescoço, o abdômen nu, o uso de cores vistosas e um turbante com duas cestinhas cheias de frutas. As alterações das vestimentas feitas pela atriz, não se deve apenas pela sua excentricidade, mas tinha a ver com a própria brasilidade, com sua natureza colorida, não devia se representar o Brasil com vestes brancas, como as baianas faziam. O colorido associado à natureza, ao Carnaval, e a toda diversidade étnica da nação, representava muito mellhor o Brasil do que o branco. A baiana, como o próprio nome diz, não deixou de ser uma figura regional, mas as alterações feitas por Carmem Miranda deram a ela a possibilidade de ser uma figura nacional (KERBER, 2005). Portanto, na ilustração podemos observar que as vestimentas puramente brancas das baianas também foram modificadas, assim como a da atriz Carmem Miranda, foram sobrepostas cores vibrantes, recortes florais de chita, na tentativa de se resgatar a iconicidade das baianas e a brasilidade do tecido de chita.

Além da imagem da personagem, o texto faz referência a festas populares: O Carnaval e o Maracatu Pernambucano. A 
chita, com seu valor de compra acessível para as camadas da população de menor poder aquisitivo e sua alegria evocada pelos florais de intenso colorido, fizeram dela a representação da própria alegria festiva, espalhando-se nos figurinos dos festejos do nosso imenso território. Conta-nos Mellão e Imbrosi (2005) que já na primeira capital da República, onde estava a maior população negra do país após a Abolição da Escravatura, o carnaval de rua se vestia de chita. Os festejos carnavalescos são comemorados em praticamente todo o Brasil e exibem em seu bojo uma multiplicidade de manifestações culturais que são capazes de movimentar, num mesmo momento, tantas manifestações artísticas diferentes. Uma dessas manifestações é ação performática do Maracatu, que representa a permanência e resistência da cultura africana. Tais festividades caracterizam a miscigenação de várias culturas, a chita é o ícone que melhor traduz o significado de brasilidade presente nestas celebrações. Pode-se dizer então que a indumentária é um dos elementos fundamentais de tais festas e que colabora profundamente para a visualidade do espetáculo, como objeto cênico emblemático capaz de compor e materializar personagens.

Assim, no que diz respeito ao juízo de valor, a imagem traz para seus leitores diversos elementos de interculturalidade, de extrema significância para nossa compreensão sobre a diversidade das manifestações artísticas e culturais do povo brasileiro.

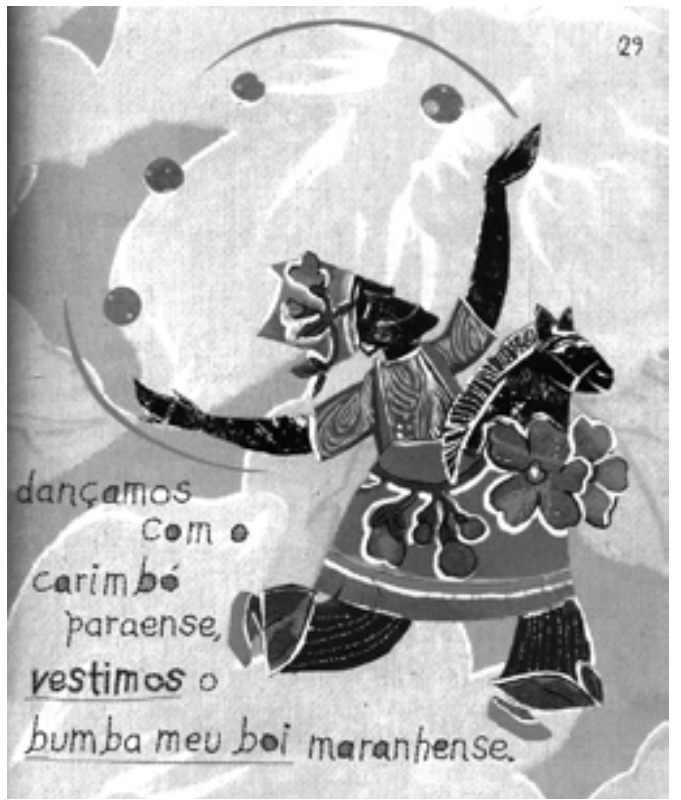


A Figura 4 apresenta-nos a imagem bidimensional de um personagem característico das festas folclóricas nordestinas. Aparentemente uma figura masculina, com turbante vermelho com ramos de flores, vestindo um traje cênico de cor verde com recortes de flor de chita vermelha, que leva à frente a figura de um animal, representando o personagem folclórico do Bumba meu boi. A figura está em movimento, fazendo acrobacias com bolinhas e festejando. O plano de fundo da ilustração é de tecido magenta com variações mais claras e manchas brancas. Novamente a imagem trabalha com a figura humana estilizada e de perfil, com a técnica da colagem para compor a figuração, no entanto, as hachuras do personagem e a coloração em preto assemelha-se muito a linguagem da xilogravura. É importante salientarmos esta linguagem artística na produção da Literatura de Cordel nordestina, uma vez que esta é uma herança cultural de grande valor para o Brasil e principalmente para o Nordeste, onde suas raízes estão fincadas. É uma literatura que contribui para o enriquecimento não só da história, como também da arte, da música, entre outras manifestações culturais nordestinas, além de ser caracterizada como um forte elemento de identidade regional.

Interpretando a imagem, é evidente a associação ao folclore e à cultura popular nordestina. Segundo os autores $\mathrm{Zu}$ con e Braga (2013, p. 76): "Desde o final do século XIX, muitos estudiosos no Brasil e no mundo, manifestavam preocupações com o registro de tudo o que fosse considerado folclórico". Para o autor, nesse período temia-se que as práticas populares tradicionais entrassem em decadência pelo contato com a cultura urbana e industrial. No entanto, por meio dos estudos dos antropólogos e dos folcloristas no decorrer dos anos, vimos que esta concepção está ultrapassada. Nesta perspectiva, Canclini (1998) defende que, apesar da cultura de massa - industrial ser ameaça às culturas tradicionais, ela não as dominou, mas hibridizou as mesmas. A cultura popular é pensada pelo autor, como o espaço em que o massivo e o folclórico hibridizam-se. Nesta linha de pensamento, as manifestações populares ocorrem no bojo desta hibridação, e sua própria essência traz essa característica. Exemplo disto, as festas populares mencionadas na imagem: Carimbó paraense e o Bumba meu boi maranhense.

O Carimbó é uma das manifestações culturais presentes no Estado do Pará. Trata-se de grupo formado por homens e mulheres que dançam, cantam, e tocam o carimbó. Segundo Cascudo (1980), a palavra carimbó é fruto da junção das palavras: 
“curi - madeira - e imbó - ôca”. Esta palavra designa o instrumento de percussão do carimbó e a própria dança. O carimbó, assim, seria uma derivação do batuque trazido pelos negros. De acordo com Salles (1969, p. 281), este ritmo seria o "gerador da imensa variedade do carimbó, talvez a principal dança africana ainda possível de se observar e estudar na Amazônia”. A vestimenta das mulheres inclui conjuntos de saias longas rodadas e muito coloridas de chita e blusas que exibem os ombros e o pescoço, confeccionadas com rendados, em geral de uma só cor. Os cabelos são enfeitados com uma rosa em um dos lados. Há também o uso de acessórios como pulseiras e colares coloridos que dão muitas voltas no pescoço e vão até a altura do umbigo. Os homens usam um lenço vermelho no pescoço, calças de uma só cor e camisas de mangas compridas tão coloridas quanto as saias das parceiras. As camisas são amarradas na cintura. Homens e mulheres dançam descalços. Para o antropólogo Salles (1969), o carimbó também constitui-se com a influência indígena, em elementos como a coreografia, música e versos, sendo considerado na Amazônia a manifestação mais evidente resultante do contato de etnias e culturas.

O Bumba meu boi, de acordo com Mário de Andrade (1982), é uma dança dramática, derivada do misticismo, mas que em seu contexto histórico mantém a religiosidade numa mistura de sagrado e profano, impregnada pela memória das culturas ibérica e moura. Nota-se na manifestação a associação ao cênico, mímicas, danças e jogos construídos com roupagens e máscaras, ou seja, a estrutura do bumba meu boi, que condensa um enredo desenvolvido de forma dramática e coreográfica em torno do tema central da morte e ressurreição do boi. A cena é composta por vários personagens, animais e figuras míticas, que provavelmente evoluíram das antigas histórias europeias, o que faz supor sua forma de representação por meio do improviso e de acrobacias.

Segundo a autora Moura (2010), na construção do personagem, o couro do boi, como é chamada a indumentária do brincante que faz dançar o boi, pode ser comparado a uma máscara de corpo inteiro, confeccionada em veludo com aplicação de bordados e ajustada a uma armação de madeira. Os bordados seguem a tradição artesanal, ricamente elaborados com miçangas, lantejoulas e contas, e sua linguagem plástica detalha paisagens, cenas históricas e santos com riqueza de detalhes. Essas imagens sagradas: figuras de santos, passagens bíblicas, ou profanas como o brasão do Maranhão, a bandeira do Brasil, podem apresentar ornamentação de flores em torno 
do bordado central. De qualquer modo as indumentárias representativas dessa dança dramática expressam nítida mistura étnica, incluindo elementos medievais, orientais, africanos e indígenas, o que se ilustra, por exemplo, pelo uso de tecidos como o veludo e a chita. Sobre as vestimentas, a autora Moura (2010, p. 101) comenta que:

A indumentária como produto da cultura popular brasileira e até certo ponto mediadora de signos e representações, imagens e imaginário do contexto em que está inserida. Considera-se que na festa popular os trajes expressam linguagem simbólica que transcende o valor funcional da roupa, sobretudo quando propõem a construção de personagens, sinalizam valores culturais ou relações com o corpo pela ornamentação, fantasia e teatralização.

Assim, a estampa chita pode ser considerada símbolo desse hibridismo da cultura de massa com a folclórica. Ela, a chita, que sempre esteve presente nos rituais folclóricos e religiosos da cultura popular, não aparece somente com aspecto funcional, de vestir, mas, como símbolo de alegria, tradição e iconicidade brasileira. Portanto, podemos concluir que a imagem ilustrativa, enquanto mediadora de conhecimento para seus leitores, traz em sua totalidade uma riqueza de detalhes e associações em que a cultura brasileira é o foco.

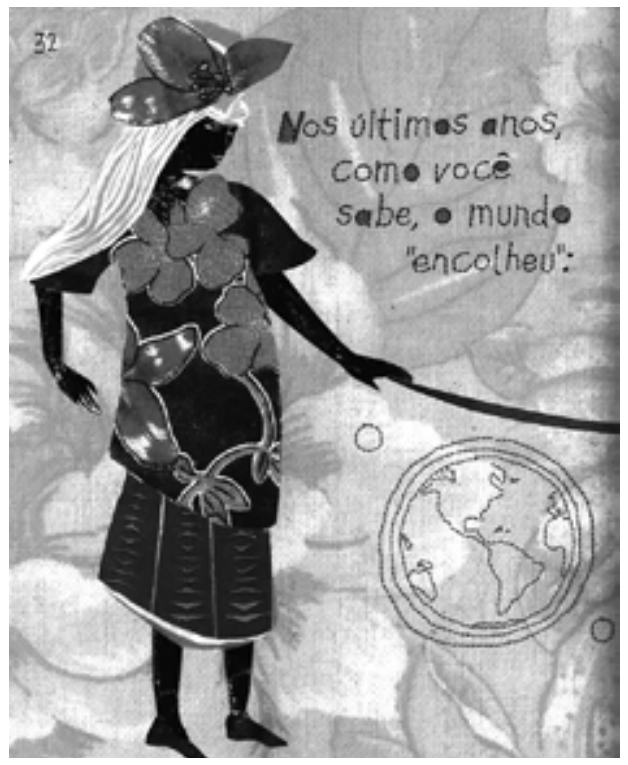


Na Figura 5, identificamos novamente a figuração humana, na imagem feminina feita de recortes. Com chapéu de chita, cabelos loiros e vestimentas simplificadas florais. Há também linhas costuradas que representam um globo, com a delimitação dos continentes. A personagem posicionada à esquerda, no primeiro plano, ocupa uma grande parte da página, destacando-se na imagem ilustrativa. O plano de fundo segue o mesmo padrão, feito de tecido floral salmão, com suas tramas visíveis. A composição da imagem é feita por meio das colagens, que simplificam as formas corporais, estilizando-as.

Interpretando a imagem e relacionando-a ao texto narrativo, a personagem em específico aparenta estar em um país tropical; suas vestes são leves, florais, coloridas e o uso do chapéu indica a sensação térmica elevada. Ela representa o olhar do estrangeiro ao Brasil, a democratização da moda e da cultura. Referente à moda, por meio dela é possível apreender fatos de uma época, bem como perceber na sua linguagem não verbal, de tecidos e estampas que constituem as roupas e o trajar, os aspectos culturais em determinado tempo e espaço. Assim, desde o século XIX, mais precisamente no século $\mathrm{XX}$, percebemos que a identificação e a divulgação da moda brasileira para o estrangeiro era associada a nossa condição tropical. Segundo Pedrosa (1998), no Brasil tudo o que indicava primitivismo, romantismo, selvagismo, isto é, no fundo, exotismo, tinha muito mais interesse e era desejado pelos estrangeiros. Podemos acrescentar que, como imagem, todo o universo de cores também era associado a esse conceito, e desfrutava de um grande apelo midiático. Logo, o que se entende é que as características plásticas das estampas brasileiras, embora muito similares as suas concorrentes estrangeiras, puderam coincidir com um discurso de brasilidade.

Sendo assim, podemos caracterizar o tecido chita apropriado na ilustração, como um elemento que mantém uma ligação direta com a noção de brasilidade, e por meio da globalização, da publicidade, dos meios de comunicação e do apelo midiático, ela desfila nas passarelas e é inserida na indústria da Moda. Como já mencionado, Zuzu Angel, estilista da década de 1960, e o próprio autor do livro em análise, Ronaldo Fraga, são exemplos de estilistas brasileiros que utilizaram as chitas em suas coleções de roupas e fizeram grande sucesso para o público estrangeiro.

No entanto, mesmo com o caráter de efemeridade das coleções de moda, a estampa chita continua a ter seu próprio valor, 
dentro ou fora da moda. Ela possui identidade própria. Ela não se perde em coleções guardadas esperando o próximo chamado da moda. A chita continua seu caminho de ícone brasileiro mesmo se a moda não a requisitar. Assim, a imagem se torna muito importante, apresentando aos seus leitores e leitoras informações sobre moda e globalização na modernidade.

Portanto, por meio da análise do livro em sua totalidade imagética e discursiva, consideramos que estavam registrados e comunicados nas apropriações do tecido chita para as visualidades, os signos e símbolos da cultura brasileira em suas diferentes interfaces, registrando as culturas populares, a modernidade e vivências cotidianas. Por meio desta operação, revelamos como o emprego da chita na criação das imagens educa as subjetividades e sensibilidades dos seus leitores, no sentido de valorizar a cultura, de entender o papel da arte na linguagem das ilustrações, como produtores de significados e conhecimentos.

Logo, o papel que tais ilustrações desempenham não se limita apenas em apresentar a história da chita como realidade, mas de articular e colocar em cena a diversidade de sentidos e significados por meio de uma linguagem artística. A arte continua sendo imprescindível nos projetos da cultura, porque quando produzida a partir de uma profunda imersão nesta, traz um diferencial em relação aos outros tipos de imagens. Concordo com Deleuze (1999) quando reconhece que a arte, diferente das demais produções, materializa atos de resistência, de desobediência e de rejeição ao discurso vigente. A arte pode ser vista como uma materialização das possíveis rupturas nas continuidades históricas no presente.

\section{Considerações finais}

Por toda esta carga artística, cultural e simbólica, a estampa chita foi digna deste estudo. Sua memória deve ser constantemente resgatada e trabalhada para que se possa ter outro olhar sobre a cultura brasileira. Com este intuito, a pesquisa, tendo como suporte a Literatura infantil focalizando em ilustrações como narrativas visuais; e como principal elemento imagético a estampa chita, provoca através de sua estética a nostalgia e resgata as raízes simbólicas e híbridas de nossa cultura. $\mathrm{Na}$ Literatura, Macabéa e Gabriela também vestiram chita. Talvez como uma tentativa de caracterizar a alma do povo brasileiro, dar lhe cor e forma. É como se a estampa chita pudesse afirmar conceitos, fazer verossimilhanças ou lutar contra tabus e conceitos preestabelecidos (SILVA, 2010). Face ao exposto, 
a utilização da chita nas narrativas infantis contém fios que "tramam contextos, alinhavam histórias, arrematam elos de nossa cultura" (CHATAIGNEIER, 2006, p. 11).

Portanto, por meio da pesquisa, consideramos que as diversas referências culturais formam um "tecido" de fundamental importância para pensarmos nossas identidades. Embora muitas vezes nos deparemos com a noção de que os objetos tradicionais são restritos às manifestações folclóricas e às culturas populares, tentamos demonstrar que estão arraigados de forma efetiva aos nossos modos de fazer, vestir, celebrar, fazendo parte, conscientemente ou não, do dia a dia do brasileiro. Mesmo na modernidade, as formas de expressões tradicionais estão muito vivas, exemplo disso se constitui o tecido Chita, que se adaptou à dinâmica das transformações modernas, assimilando o novo e sendo apropriada e apresentada de diferentes formas, sem perder sua força. Quando compreendemos que cada grupo social tem suas dinâmicas culturais, e que nossas próprias referências são conceitos construídos historicamente, sabemos que um único artefato possui em sua singularidade um sistema cultural simbólico, com significados particulares.

\section{Referências}

ANDRADE, Mário. Danças dramáticas. Belo Horizonte: Itatiaia, 1982.

ARNHEIM, Rudolf. Arte e percepção visual: uma psicologia da visão criadora. São Paulo: Nova versão, 2006.

BARBOSA, Ana Mae. Inquietações e mudanças no ensino da arte. São Paulo: Cortez, 2008.

BONADIO, Maria Claudia. Moda e publicidade no Brasil dos anos 1960. São Paulo: Editora nVersos, 2014.

BOURDIEU, Pierre. A distinção: Crítica social do julgamento. Porto Alegre: Zouk, 2007.

BURKE, Peter. Hibridismo cultural. Tradução Leila Souza Mendes. Pelotas, RS: Editora Unisinos, 2003.

CANCLINI, Néstor Garcia. As Culturas Populares no Capitalismo. São Paulo: Brasiliense, 1998. . Culturas Híbridas: estratégias para entrar e sair da modernidade. São Paulo: EDUSP, 2011.

CASCUDO, Luís da Câmara. Dicionário do Folclore Brasileiro. 8. ed. São Paulo: Global, 1980.

CASTANHA, Marilda. A linguagem visual no livro sem texto. In: OLIVEIRA, Ieda de. (Org.). O que é qualidade em ilus- 
tração no livro infantil e juvenil: com a palavra o Ilustrador. São Paulo: Editora DCL, 2008. p. 140-151.

CASTELLS, Manuel. O poder da identidade. Tradução Klaus Brandini Gerhardt. São Paulo: Paz e Terra, 1999.

CHATAIGNIER, Gilda. Fio a fio. Tecidos, moda e linguagem. São Paulo: Estação das Letras e Cores, 2006.

. História da Moda no Brasil. São Paulo: Estação das Letras e Cores, 2010.

DELEUZE, Gilles. Conversações. São Paulo: Editora 34, 1999. FELDMAN, Edmund Burke. Metodologia de trabalho. São Paulo: USP, 1993.

FITTIPALD, Ciça. O que é uma imagem narrativa. In: OLIVEIRA, Ieda de. (Org.). O que é qualidade em ilustração no livro infantil e juvenil: com a palavra o Ilustrador. São Paulo: Editora DCL, 2008. p. 93-123.

GOBEL, Anna; FRAGA, Ronaldo. Uma festa de cores: Memórias de um tecido brasileiro. Belo Horizonte: Editora $\mathrm{Au}-$ têntica, 2014.

GOMES, Paola. A formação de visualidade, imaginário e estereótipos. Revista da Fundarte, Montenegro, Rio Grande do Sul, ano II, v. II, n. 4, jul/dez 2002.

HALL, Stuart. A identidade cultural na pós-modernidade. Rio de Janeiro: DP\&A, 2006.

KERBER, Alessander. Carmen Miranda: Entre representações da identidade nacional e de identidades regionais. Revista Artcultura, Uberlândia, Minas Gerais, v. 7, n. 10, p. 121-132, jan/jun 2005.

MAIA, Antônio Cavalcanti. Diversidade cultural, identidade nacional brasileira e patriotismo constitucional, 2009. Disponível em: <http://www.casaruibarbosa.gov.br/dados/DOC/ palestras/Diversidade_Cultural/FCRB_DiversidadeCulturalBrasileira_AntonioCavalcanti.pdf >. Acesso em: set. 2015.

MELLÃO, Renata; IMBROSI, Renato. Que chita bacana. São Paulo: Editora A Casa, Museu do Objeto brasileiro, 2005.

MOURA, Regina. Sobre a indumentária na festa popular: imagens, signos e fantasias. Textos Escolhidos de Cultura e Arte Populares, Rio de Janeiro, v. 7, n. 1, p. 101-108, maio 2010.

NEIRA, Luz Garcia. Estampas na tecelagem brasileira: Da origem à originalidade. 2012. $307 \mathrm{f}$. Tese (Doutorado em Arquitetura) - Faculdade de Arquitetura, Universidade de São Paulo, São Paulo, 2012.

. A invenção da moda brasileira. Caligrama: Revista de Estudos e Pesquisas em Linguagem e Mídia, São Paulo, 
v. 4, n. 1, 2008. Disponível em: <http://www.revistas.usp. br/caligrama/article/view/68123>. Acesso em: maio 2016.

ORTIZ, Renato. Cultura brasileira e identidade nacional. São Paulo: Brasiliense, 1985.

PEDROSA, Mário. Acadêmicos e Modernos: Textos escolhidos III. São Paulo: Edusp, 1998.

SALLES, Vicente. Carimbó: trabalho e lazer do caboclo. Revista Brasileira do Folclore, Rio de Janeiro, 1969.

SILVA, Emanuela Francisca Ferreira. Estampa chita e cesura: Linguagem não-verbal e suas diversas interfaces comunicacionais, Revista Encontro de Vista, 5. ed., p. 96-107, 2010. Disponível em: <http://www.encontrosdevista.com.br/Artigos/Antigos/Emanuela_Francisca_Estampa_chita_e_cesura-final.pdf/>. Acesso em: abr. 2015.

SIMILI, Ivana Guilherme. A primeira-dama Maria Theresa Goulart e o costureiro Dener: a valorização da moda nacional. História e Cultura, Franca, São Paulo, v. 3, n. 1, abr. 2014. Disponível em: <http://periodicos.franca.unesp.br/ index.php/historiaecultura/article/view/993>. Acesso em: maio 2016.

ZUCON, Otávio; BRAGA, Geslline Giovana. Introdução às culturas populares no Brasil. Curitiba: InterSaberes, 2013.

Recebido em: 31/o1/16

Aceito em: 06/05/16 


\section{IVANA GUILHERME SIMILI}

ivanasimili@ig.com.br

Fez a graduação, o mestrado e o doutorado em História, na Universidade Estadual Paulista Júlio de Mesquita Filho - Unesp-Assis. É professora associada da Universidade Estadual de Maringá. É professora do programa de pós-graduação em História (PPH-Uem), na linha de pesquisa Fronteiras, Populações e Bens Culturais.

\section{PRISCILA BARBEIRO}

priscilabarbeiro@hotmail.com

Mestranda no Programa de Pós-graduação em Artes Visuais da Universidade do Estado de Santa Catarina (PPGAV/UDESC). Graduada em Artes Visuais pela Universidade Estadual de Maringá-PR. Realizou pesquisas de iniciação científica na área de arte e cultura, com foco no ensino intercultural e na estética do cotidiano. 